(0.25 (95\% CI 0.49 to 0.008 ) but not in the healthy participants. TNF- $\alpha$, IL-17 and CRP were not significantly increased with exercise in either group. No significant differences were found between groups for the change (pre- to post-walk) in any inflammatory markers (CRP: $p=0.07$; IL-6: $p=0.51$; TNF- $\alpha$ : $p=0.22$; IL-17: $p=0.44$ ).

Abstract S30 Table 1 Baseline and post-walk systemic inflammatory mediators in patients with Chronic Obstructive Pulmonary Disease (COPD) and healthy comparators

\begin{tabular}{|c|c|c|c|}
\hline Marker & Rest concentration & Post walk concentration & p Value \\
\hline \multicolumn{4}{|l|}{ COPD $(n=16)$} \\
\hline $\mathrm{CRP}(\mathrm{mg} / \mathrm{l})$ & 3.77 (1.67 to 8.49 ) & 4.75 (1.99 to 11.08$)$ & 0.56 \\
\hline IL-6 (pg/ml) & $2.80(2.00$ to 3.25$)$ & $2.95^{*}(2.03$ to 3.63$)$ & 0.04 \\
\hline TNF- $\alpha(\mathrm{pg} / \mathrm{ml})$ & $8.25(5.80$ to 10.13$)$ & 7.10 (4.95 to 10.03$)$ & 0.64 \\
\hline IL-17 (pg/ml) & 52.52 (35.92 to 82.61$)$ & 55.16 (47.85 to 79.17$)$ & 0.62 \\
\hline \multicolumn{4}{|l|}{ Healthy $(n=16)$} \\
\hline CRP (mg/l) & $1.15(0.61$ to 2.60$)$ & $1.60(0.68$ to 2.60$)$ & 0.72 \\
\hline IL-6 (pg/ml) & $2.70(2.00$ to 3.00$)$ & $2.00(2.00$ to 2.95$)$ & 0.73 \\
\hline $\mathrm{TNF}-\alpha(\mathrm{pg} / \mathrm{ml})$ & 5.15 (4.00 to 9.18$)$ & 7.05 (4.00 to 9.08$)$ & 0.64 \\
\hline IL-17 (pg/ml) & $65.50(52.20$ to 82.43$)$ & $70.40(57.78$ to 88.28$)$ & 0.31 \\
\hline
\end{tabular}

${ }^{*} p<0.05$ compared with rest concentration in the COPD group; all baseline concentrations (between groups) and other pre-post changes (within groups) were not significantly different $(p>0.05)$.

COPD, chronic obstructive pulmonary disease; CRP, C-reactive protein, IL-6, Interleukin-6,

TNF- $\alpha$, IL-17, Interleukin-17; mg/l, milligrammes per Litre; pg/ml, picogrammes per millilitre.

Conclusion Despite a significant increase in IL-6, the magnitude of the systemic inflammatory response to matched absolute workloads in COPD patients is not greater than in healthy comparators.

\section{S31 ENERGY EXPENDITURE AND PHYSICAL ACTIVITY LEVELS DURING AN 8-WEEK PULMONARY REHABILITATION PROGRAMME}

doi:10.1136/thoraxjnl-2011-201054b.31

J L Canavan, K A Ingram, R P Fowler, A L Clark, P Marns, M S Patel, S S Kon, W D-C Man. Harefield Pulmonary Rehabilitation Team and Respiratory Biomedical Research Unit, Royal Brompton \& Harefield NHS Foundation Trust, Harefield, Middlesex, UK

Introduction The IMPRESS standards for pulmonary rehabilitation (PR) recommend that programmes should include two supervised exercise sessions per week for at least 4 weeks, and written prescriptions of exercise training with evidence of progress reported in training diaries. However, subjective self-reported assessment is associated with bias, and may not accurately represent actual exercise intensity and duration. Patients require familiarisation with equipment and training regimes during a PR programme. We hypothesised that active energy expenditure and time spent in at least moderate physical activity, measured objectively with a validated activity monitor (SenseWear armband-SWA), would show no significant increase within the first 4 weeks of a PR programme. Method 34 COPD patients (17M: 17F), starting an 8-week outpatient PR programme consisting of two supervised exercise sessions per week, consented to wearing SWA for one entire exercise training session each week for the whole PR programme (T1-T8). Output from the SWA includes active energy expenditure (AEE) and time spent in at least moderate intensity physical activity (PA time) that is, >3.0 METS. AEE and PA time recorded at T1, T4 and T8 were evaluated using Friedman tests. Incremental shuttle walk (ISW) and COPD Assessment Test (CAT) were measured before (T0) and after (T9) PR. Differences in pre to post-outcome measures were assessed using paired $t$ tests.

Results Results are presented as median (25th, 75th percentile). There was no significant difference in PA time or AEE between T1 (11.5 (4.0 to 27.0$) \mathrm{min} ; 43.5$ (19.5 to 124.3$) \mathrm{Kcal}$ ) and T4 (10.5 (7.5 to 24.8 ); 48.5 (32.3 to 106.0$) \mathrm{Kcal}, \mathrm{p}>0.05$ ) despite progress documented in training diaries. PA time significantly increased from T1 to T8 (19.5 (8.8 to 34.0) $\mathrm{min}, \mathrm{p}=0.02$ ), as did AEE (92.0 (37.0 to 146.3) Kcal, $p=0.006)$. Following $P R$ there was also a significant improvement in ISW (52.1 (95\% CI 29.2 to 75.1$) \mathrm{m}, \mathrm{p}<0.001)$ and CAT score ( -3.0 ( $95 \%$ CI 0.3 to 5.8$) \mathrm{p}=0.03$ ).

Conclusion 4-week PR programmes may be insufficient in duration for patients to become familiarised with equipment and exercise regimes.

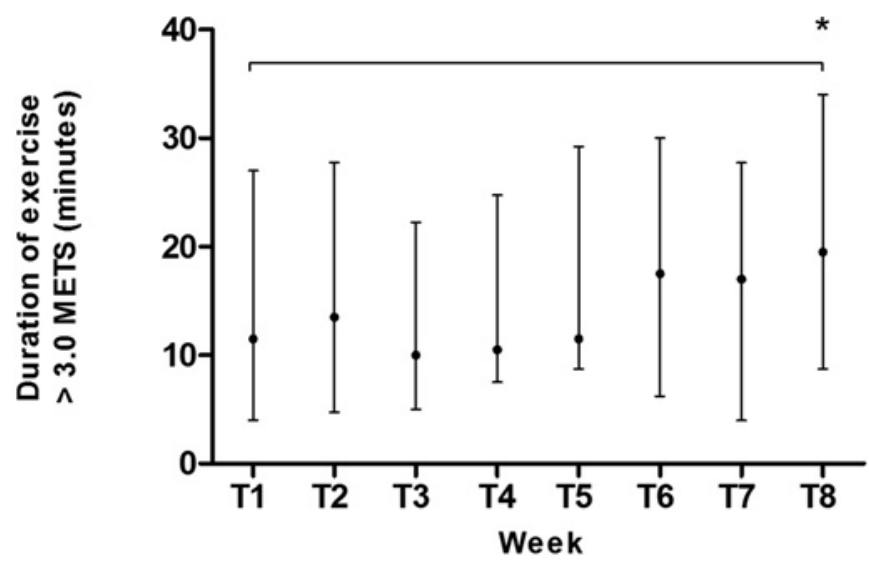

Abstract S31 Figure 1 PA time during pulmonary rehabilitation classes over an 8-week outpatient programme. Data presented as median (IQR) ${ }^{*} p<0.05$ significant difference compared to week 1 .

\section{Novel mechanisms driving airway inflammation in asthma

\begin{tabular}{l}
\hline S32 LOSS/INHIBITION OF THE aVb5 INTEGRIN REDUCES \\
ALLERGEN-INDUCED INCREASES IN AIRWAY SMOOTH \\
MUSCLE MASS IN IN VIVO MODELS OF ASTHMA
\end{tabular}

doi:10.1136/thoraxjnl-2011-201054b.32

${ }^{1} \mathrm{~A}$ L Tatler, ${ }^{1} \mathrm{~A} E \mathrm{E}$ John, ${ }^{1} \mathrm{~L}$ Jolly, ${ }^{1} \mathrm{~A}$ Habgood, ${ }^{1} \mathrm{~J}$ Porte, ${ }^{1} \mathrm{~A} J \mathrm{~J}$ Knox, ${ }^{2} \mathrm{X}$ Huang, ${ }^{2} \mathrm{D}$ Sheppard, ${ }^{1} \mathrm{G}$ Jenkins. ${ }^{1}$ University of Nottingham, Nottingham, UK; ${ }^{2}$ University of California San Francisco, San Francisco, USA

Airway remodelling is a common feature of severe asthma. Transforming growth factor- $\beta$ (TGF- $\beta$ ) is a pro-fibrotic, pleiotropic cytokine implicated in airway remodelling. TGF- $\beta$ is sequestered in the extracellular matrix as a latent complex and requires activation to function. We have previously shown that contraction agonists cause aVß5-mediated TGF- $B$ activation by human airway smooth muscle cells. The study aims were to investigate the role of the aVß5integrin in airway remodelling in vivo using two distinct mouse models of asthma. A blocking antibody directed against the aVß5 was used in the ovalbumin (OVA) model of asthma. Mice were sensitised with OVA/Alum on days 0 and 12, then challenged byoropharyngeal administration of OVA 10 times over 2 weeks. The antiaVß5antibody or an isotype matched control antibody was administered for the duration of the OVA challenges. The second invivo model utilised itg $5^{-1-}$ mice. Aspergillous fumigatus antigen preparation was administered intra-nasally $(10 \mu \mathrm{g} / \mathrm{mice})$ to $i \operatorname{tg} b 5^{-/-}$and wild type controls 9 times over a 21-day period. a-Smooth muscle actin (a-SMA) was quantified in lung sections from both studies by immunofluorescence. Murine airway smooth muscle cells express $\mathrm{aVB5}$ integrin and can activate TGF- $B$ in vivo in response to allergen challenge as measured by $\alpha v \beta 5$ and phospho-Smad2 immunostaining. Treatment with both OVA and Asp.f resulted in an increase in a-SMA staining around the smaller airways. The aVB5blocking antibody significantly reduced a-SMA staining compared with the 
isotype control antibody. Furthermore, itg $b 5^{-/-}$mice had significantly less a-SMA around their airways than wild type control mice in response to Asp.f treatment. However, both itgb5 $5^{-/-}$andantiaVß5 treated mice had significantly more airway inflammation and more inflammatory cells present in the bronchoalveolar lavage compared with their matched controls. These data provide evidence that airway smooth muscle cells can activate TGF- $B$ in vivo. Inhibition of, or genetic loss of, the aVß5 integrin significantly reduces allergen-induced increases in airway smooth muscle mass, however, peribronchial inflammation is increased consistent with the known effects of TGF $\beta$. Targeted inhibition of the aVß5 integrin may reduce airway remodelling, but global inhibition is unlikely to be useful due to the enhanced inflammatory response.

\section{S33 VITAMIN D AND AIRWAY REMODELLING IN PAEDIATRIC SEVERE THERAPY RESISTANT ASTHMA}

doi:10.1136/thoraxjnl-2011-201054b.33

${ }^{1} \mathrm{~A}$ Sjoukes, ${ }^{1} \mathrm{~A}$ Gupta, ${ }^{2} \mathrm{~T}$ Oates, ${ }^{1} \mathrm{~A}$ Bush, ${ }^{1} \mathrm{~S}$ Saglani. ${ }^{1}$ Department of Respiratory Paediatrics, Royal Brompton Hospital, London, UK; ${ }^{2}$ National Heart \& Lung Institute, Imperial College, London, UK

Background Serum vitamin D levels have been related to asthma control and medication use in children with mild to moderate disease, but little is known about the relationship between serum vitamin $\mathrm{D}$ levels and airway remodelling and mucosal inflammation in asthma. We hypothesised that lower serum vitamin $\mathrm{D}$ levels would be associated with increased airway inflammation and remodelling and lower lung function in children with severe therapy resistant asthma (STRA).

Methods Nineteen children aged between 6 and 16 years with STRA underwent spirometry, fiberoptic bronchoscopy, endobronchial biopsy, and measurement of serum vitamin $\mathrm{D}\left(25(\mathrm{OH}) \mathrm{D}_{3} \mathrm{nmol} / \mathrm{l}\right)$. Endobronchial biopsies stained with $\mathrm{H} \& \mathrm{E}$ were used to quantify airway remodelling (reticular basement membrane thickness, smooth muscle mass and epithelial shedding). Immunohistochemistry was used to quantify smooth muscle cell proliferation using proliferating cell nuclear antigen, and inflammatory cells (eosinophils, neutrophils and mast cells).

Results Seventeen of 19 children with STRA were vitamin D insufficient $(<50 \mathrm{nmol} / \mathrm{l})$, median (range) serum $25(\mathrm{OH}) \mathrm{D}_{3} \quad 29$ $(21-39) \mathrm{nmol} / \mathrm{l}$. There was no relationship between serum $25(\mathrm{OH})$ $\mathrm{D}_{3}$ and submucosal eosinophils, neutrophils or mast cells. Airway smooth muscle mass was inversely related to serum $25(\mathrm{OH}) \mathrm{D}_{3}$ $(\mathrm{r}=-0.6, \mathrm{p}=0.007)$ (Abstract S33 figure 1), but there was no relationship between vitamin $\mathrm{D}$ levels and reticular basement membrane thickness or epithelial shedding. Lung function was not related to

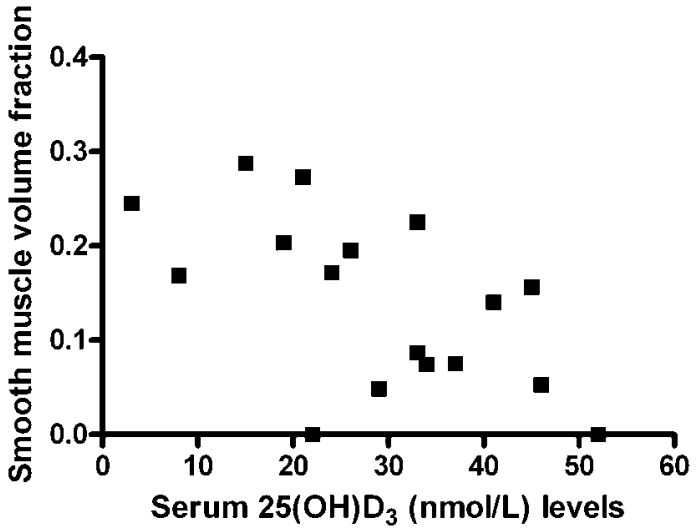

Abstract S33 Figure 1 Correlation between volume fraction of airway smooth muscle and serum $25(\mathrm{OH}) \mathrm{D}_{3}$ in paediatric STRA. serum vitamin $\mathrm{D}$ levels, however bronchodilator reversibility was inversely related to serum $25(\mathrm{OH}) \mathrm{D}_{3}$ levels $(\mathrm{r}=-0.53, \mathrm{p}=0.02)$.

Conclusions Vitamin D insufficiency is common in children with STRA. Lower vitamin D levels in children with STRA were associated with increased airway smooth muscle and increased bronchodilator reversibility. Randomised controlled trials of vitamin D supplementation are warranted in paediatric STRA.

\section{S34 THE ADHESION RECEPTOR CADM1 ON MAST CELLS MEDIATES ADHESION TO LUNG FIBROBLASTS AND SMOOTH MUSCLE}

doi:10.1136/thoraxjnl-2011-201054b.34

E P Moiseeva, K Roach, M L Leyland, P Bradding. University of Leicester, Leicester, UK

Introduction and Objectives Cell adhesion molecule 1 (CADM1) contributes to cell-cell adhesion, viability and adhesion-induced degranulation in mast cells. We found that it is expressed as three alternatively spliced isoforms (major SP4, SP1 and minor SP6) in human lung mast cells (HLMCs). Here we investigated the role of CADM1 isoforms in the adhesion of mast cells to primary airway smooth muscle cells (ASM) and lung fibroblasts (LF).

Methods Modulation of CADM1 expression was investigated in transient transfection or adenoviral delivery in the mast cell line HMC-1 and HLMCs. Cells with overexpressed CADM1 isoforms or downregulated CADM1 were examined in cell adhesion assays.

Results CADM1 RNA interference in HMC-1 resulted in $60 \%$ reduction of surface CADM1 and complete loss of CADM1 determined by FACS and Western blotting, respectively, 6 days after transduction. This decrease in CADM1 expression reduced adhesion of transduced HMC-1 cells to ASM and LF by $42 \%$ and $50 \%$, respectively. Downregulation of CADM1 in HLMCs reduced adhesion to ASM by 39\%. HMC-1 cells transfected with SP1 (exon 8/9/ 11) and SP6 (exon 8/9/10/11) showed lower adhesion to LF compared to cells transfected with SP4 (exon 8/11). No differences in adhesion to ASM were found. When SP4 and SP1 isoforms were overexpressed up to $206 \%$ and $148 \%$ on the cell surface 6 days post transduction by viral delivery, this CADM1 overexpression did not change adhesion to ASM. However, increased levels of SP4 isoform increased mast cell adhesion to LF by $37 \%$. Thus, CADM1 isoforms affected adhesion to LF differently. The CADM1 counter-receptors, examined by Western blotting, are nectin-3 on ASM and CADM1 + nectin-3 on LF.

Conclusions CADM1 contributes significantly to mast cell adhesion to ASM and LF. Mast cell adhesion to ASM is likely to be limited by the number of counter-receptors on ASM. In contrast, mast cell adhesion to LF is determined by the levels of SP4 isoform on mast cells. Increased levels of other CADM1 isoforms do not increase adhesion to LF. It is likely that increased levels of longer SP1 and SP6 isoforms in proportion to the CADM1 pool decrease mast cell adhesion to LF.

\section{S35 RAPAMYCIN INHIBITS IL-33-INDUCED, NUOCYTE-DRIVEN AIRWAY INFLAMMATION}

doi:10.1136/thoraxjn--2011-201054b.35

A S Mirchandani, R J Salmond, C J Bain, F Y Liew. University of Glasgow, Glasgow, UK

Introduction IL-33 is an innate cytokine that promotes Th2 responses in both the innate and the adaptive immune systems, with an established role in allergic airway inflammation. ${ }^{1}$ The signalling pathway of IL-33/ ST2 is incompletely understood and the cells driving IL-33-mediated inflammation have remained elusive. Nuocytes, also known as natural helper cells, are a novel 